\title{
Assessment of factors affecting and causing Hepatitis B in Balochistan- Pakistan
}

\author{
Hayat Ullah ${ }^{1}$, Asad Ullah ${ }^{2}$ and Muhammad Waseem Khan ${ }^{1 *}$ \\ 1. Department of Biotechnology, Faculty of Life Sciences \& Informatics, Balochistan University of Information \\ Technology, Engineering \& Management Sciences Quetta, Balochistan-Pakistan \\ 2. Department of Microbiology, Faculty of Life Sciences \& Informatics, Balochistan University of Information \\ Technology, Engineering \& Management Sciences Quetta, Balochistan-Pakistan \\ *Corresponding author's email: muhammad.waseem@buitms.edu.pk \\ Citation \\ Hayat Ullah, Asad Ullah and Muhammad Waseem Khan. Assessment of factors affecting and causing Hepatitis \\ B in Balochistan-Pakistan. Pure and Applied Biology. Vol. 9, Issue 1, pp471-477. \\ http://dx.doi.org/10.19045/bspab.2020.90052
}

\begin{tabular}{llll}
\hline \hline Received: 07/08/2019 & Revised: 25/10/2019 & Accepted: 05/11/2019 & Online First: 18/11/2019 \\
\hline \hline
\end{tabular}

\section{Abstract}

Hepatitis B infection caused by HBV is transmitted through HBV contaminated blood and body fluids, is a major communicable disease of vertical transmission. HBV infection is endemic in Asia pacific regions including Pakistan. The main objective of this study was to determine most common factors affecting and causing Hepatitis B. A cross sectional research study was conducted where blood samples were taken from suspected Hepatitis B individuals for diagnosis and confirmation of HBV. Social and demographical factors were studied with the help of questionnaire. Hepatitis B disease is promoted through sharing of equipment and environment with HBV infected individuals. Smoking either active or passive was significantly positively correlated with Hepatitis B disease whereas education and socioeconomic status were negatively correlated with Hepatitis B. The study conclude that unhygienic practices particularly in dental clinics substantially increase the risk of Hepatitis B. The present study serves as a primary data and will be helpful in future research on Hepatitis B in Balochistan.

Keywords: Communicable diseases; Environmental health; Epidemiology; Hepatitis B Virus; Infection; Prevalence

\section{Introduction}

Hepatitis is an inflammation and most commonly caused by viral infection. More than 240 million people worldwide have chronic Hepatitis B virus (HBV); with the highest rates of infection in Asia and Africa, placing them at increased risk of developing cirrhosis, hepatic decompensation and hepatocellular carcinoma (HCC) [1]. Approximately 45\% of the world's population live in regions that are highly endemic for HBV infection, most infections in these regions are acquired parentally or during early childhood [2]. Infection with HBV can cause acute as well as chronic infection that may lead to liver failure or hepatocellular carcinoma. Several studies have reported that Hepatitis B virus can replicate in human pancreatic tissue causing impairments of pancreatic function [3-5].

HBV is endemic in Pakistan with prevalence of $2.5 \%$. The country has most cases of chronic infections where 8.6 million (4.8\% of the population) are affected with Hepatitis B and C diseases. The most effected province was Balochistan with the prevalence of $4.3 \%$. Although, Hepatitis B disease is asymptomatic in early silent phase but 
vertical transmission in early childhood is the main causative factor of $\mathrm{HBV}$ and common in highly endemic areas where infants are born to HBV infected mothers [6].

Household contact with chronically infected HBV members of the family and occupational health care exposure to blood products being used in hospitals, laboratories and haemodialysis are other common risk factors of Hepatitis B [7]. Whereas, common mode of transmission particularly in rural areas of Pakistan is attributed to reuse of syringes and contaminated equipment. Pakistan is among the top syringe consuming countries where 2.4 billion syringes are used and reused every year spreading $\mathrm{HBV}$ and $\mathrm{HCV}$ infections [1].

Specific socio-demographic characteristics, Hepatitis B knowledge associated with age and sex differences along with Intravenous drug use (IDU) are some most important factors widely assessed with HBV transmission in different research settings. However, more studies at different clinical settings are required to gain further knowledge about region specific transmission patterns and contributing factors. This study was conducted with the aim to determine most common factors affecting and causing Hepatitis B in the region.

\section{Materials and methods}

The current cross sectional research study was conducted (January 2017 - October 2017) in department of biotechnology, Balochistan University of Information Technology Engineering and Management Sciences (BUITEMS). The study was based on blood samples collected from suspected Hepatitis B individuals having symptoms of fever, abdominal pain, loss of appetite, weakness, fatigue and yellowing of skin. All the study individuals $(\mathrm{N}=400$, suspected Hepatitis B patients) were referred by out patient departments (OPDs) of various hospitals through their physicians to Assa Lab, Saleem medical complex, Balochistan, Pakistan for the diagnosis and confirmation of Hepatitis B. Social and demographical factors were also collected with the help of questionnaires. All individuals were included in the study after obtaining their informed consent. The study was approved by ethical committee of BUITEMS.

We used Hepatitis B virus surface antigen (HBsAg) rapid test kit for the diagnosis and confirmation of HBV. HBsAg kit method have about $98 \%$ accuracy with high specificity and positive predictive values. The method is user friendly, cheap and impose least discomfort to the patient as only small specimen size is required. The results of the methods are reliable and can be confirmed by enzyme-linked immunosorbent assay (ELISA) and polymerase chain reaction (PCR) methods. About five $\mathrm{ml}$ of blood was collected with disposable sterile syringe from each suspected Hepatitis B individual via aseptic veni-puncture. The sera from the blood samples were separated to avoid hemolysis and stored at $-20^{\circ} \mathrm{C}$ until tested.

Samples were brought to room temperature prior to testing and analyzed according to manufacturer's recommendations. $120 \mu \mathrm{L}$ sample was drawn onto the sample well of the cassette using the pipette. After waiting 10-20 minutes the results were ready for reading. It was made sure to read the results before 20 minutes. The results provided by HBV kit were analysed as either HBV positive or HBV negative.

\section{Results}

The age of all study individuals ranged from 16.7 years to 55.2 years (mean 33.5 years, SD 8.3). $69 \%$ of individuals $(\mathrm{N}=$ 276) participated in the study were male and $31 \%$ of individuals $(\mathrm{N}=124)$ were female. The characteristics of all individuals $(\mathrm{N}=400)$ included in the study are shown in (Table 1).

Out of total 400 suspected Hepatitis B individuals $33.7 \%(\mathrm{~N}=135)$ individuals were confirmed as serologically positive for $\mathrm{HBV}$. The prevalence of HBV positive individuals was higher in male individuals 
$(40.8 \%, \mathrm{~N}=102)$ than female individuals $(22 \%, \mathrm{~N}=33)$ (Figure 1).

The age of individuals confirmed as serologically positive for HBV ranged from 18.2 years to 53.5 years (mean 32.7 years, SD 8.5). The characteristics of individuals confirmed as serologically positive for HBV $(\mathrm{N}=135)$ are shown in (Table 2).

HBV was more common in illiterate (no elementary school education) individuals $(39.3 \%, \mathrm{~N}=53)$ than educated individuals. According to study results, education was significantly negatively correlated to Hepatitis B. Individuals having elementary school education were more effected (20.0 $\%, \mathrm{~N}=27$ ) by Hepatitis B comparatively higher than individuals having secondary school education (17.8\%, N=24) than having higher secondary education (17.0 $\%, \quad \mathrm{~N}=23$ ), while individuals having bachelors level (university degree education) were least effected $(5.9 \%, \mathrm{~N}=8)$ by Hepatitis B (Table 2).

Hepatitis B disease was more common in individuals with history of active smoking $(52.6 \%, \mathrm{~N}=71)$ and passive smoking (36.3 $\%, \mathrm{~N}=49)$ while only $(11.1 \%, \mathrm{~N}=15)$ indviduals were not smoking. Also, HBV was most common in individuals who ever had dental care $(44.4 \%, \mathrm{~N}=60)$ (Table 2). Hepatitis B prevalence was more common in individuals with low socioeconomic status $(88.9 \%, \mathrm{~N}=120)$ having monthly income less than 30 thousand (K) PKR (Pakistani rupees). Hepatitis B was positively correlated with socioeconomic status having less individuals in higher socioeconomic class than lower socioeconomic class (Table 2).

Table 1. Characteristics of all individuals $(N=400)$ participated in the study

\begin{tabular}{|c|c|c|}
\hline & Number of individuals & Percentage of individuals \\
\hline Age (years): mean (SD) & $33.5(8.3)$ & \\
\hline Gender: & & 69.0 \\
\hline Male & 276 & 31.0 \\
\hline Female & 124 & 12.7 \\
\hline Education: & & 22.0 \\
\hline Bachelors $^{\text {a }}$ & 51 & 27.0 \\
\hline Higher Secondary Education & 88 & 15.5 \\
\hline Secondary School Education & 108 & 22.8 \\
\hline Elementary School Education & 62 & \\
\hline No Education & 91 & 18.5 \\
\hline Dental care procedure: & & 81.5 \\
\hline Yes & 74 & 32.7 \\
\hline No & 326 & 41.8 \\
\hline Socioeconomic status: ${ }^{\mathbf{b}}$ & & 25.5 \\
\hline$<10$ & 131 & \\
\hline $11-30$ & 167 & 28.0 \\
\hline$>30$ & 102 & 41.3 \\
\hline Smoking status: & & 30.7 \\
\hline Active smoking & 112 & \\
\hline Passive & 165 & \\
\hline No smoking & 123 & \\
\hline
\end{tabular}

${ }^{\mathrm{a}}$ University degree, ${ }^{\mathrm{b}}$ Thousand Pakistani rupees per month 


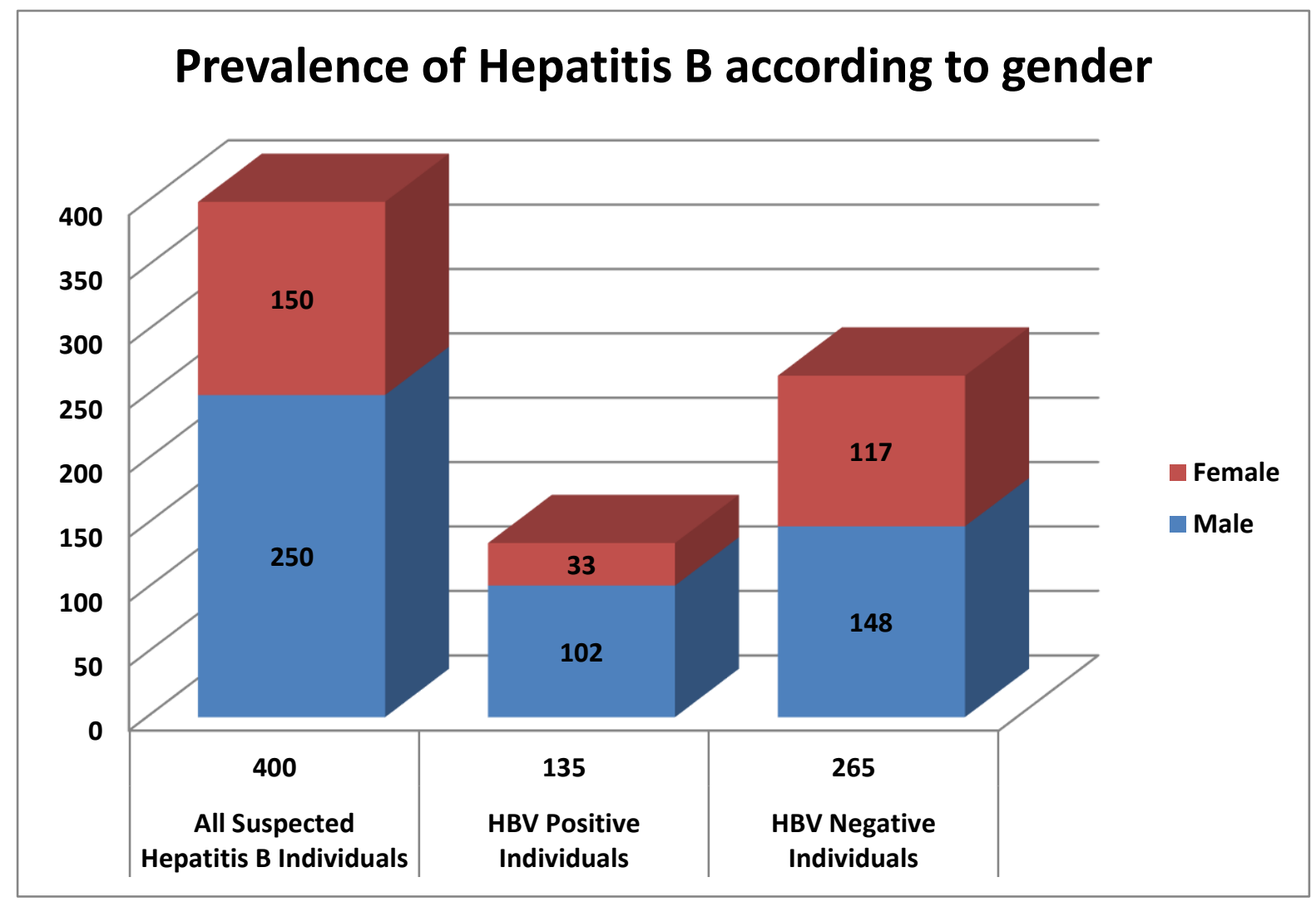

Figure 1. Prevalence of Hepatitis B according to gender

Table 2. Characteristics of individuals $(N=135)$ confirmed as serologically positive for HBV

\begin{tabular}{|c|c|c|}
\hline & Number of individuals & Percentage of individuals \\
\hline Age (years): mean (SD) & $32.7(8.5)$ & \\
\hline Gender: & & 75.6 \\
\hline Male & 102 & 24.4 \\
\hline Female & 33 & 5.9 \\
\hline Education: & 8 & 17.0 \\
\hline Bachelors $^{\text {a }}$ & 23 & 17.8 \\
\hline Higher Secondary Education $_{\text {Secondary School Education }}$ & 24 & 20.0 \\
\hline Elementary School Education & 27 & 39.3 \\
\hline No Education & 53 & 44.4 \\
\hline Dental care procedure: $^{\text {Yes }}$ & & 55.6 \\
\hline No & 60 & \\
\hline Socioeconomic status: & & \\
\hline$<10$ & 75 & 39.3 \\
\hline $11-30$ & 53 & 49.6 \\
\hline$>30$ & 67 & 11.1 \\
\hline Smoking status: & 15 & 52.6 \\
\hline Active smoking & 71 & 36.3 \\
\hline Passive & 49 & 11.1 \\
\hline No smoking & 15 & \\
\hline
\end{tabular}

${ }^{\mathrm{a}}$ University degree, ${ }^{\mathrm{b}}$ Thousand Pakistani rupees per month 


\section{Discussion}

Hepatitis B is common infectious disease in undeveloped, developing and resource poor countries. We studied clinical, social and demographical risk factors associated with Hepatitis B. Hepatitis B is male dominant disease and the disease was more dominant in middle age individuals. The male to female ratio is higher and $\mathrm{HBV}$ disproportionately strikes more men than women worldwide. The dominance in middle age particularly in males may be due to the fact that majority of female individuals of the populations in Pakistani society prefer to stay at home most of the time while male individuals are more socially active and interactive that may increase the risk of catching the HBV from suspected or diseased individuals. In addition, although natural history of HBV infection vary with age, but $\mathrm{HBV}$ is asymptomatic in early silent phase. Also, the duration of this phase may be for many years and acute Hepatitis B is often unrecognized in children younger than five years old. Clinical acute Hepatitis B is more frequent in adults than children and probability of becoming chronic carrier of Hepatitis B is greater in children than adults [8-12].

According to our study results, Hepatitis B was more common in illiterate (no elementary school education) individuals than educated individuals. Also, education was significantly negatively correlated to Hepatitis B. Educated individuals tend to have more awareness comparatively better than un-educated individuals and having better understandings of living in a healthy and clean environment [13].

There was no significant association between body mass index (BMI) and Hepatitis B. Hepatitis B was more prevalent in individuals with normal BMI score. Although, individuals with overweight, underweight and obesity had also Hepatitis B, but the proportion was significantly smaller. These results might be due to chance findings and may not be explained.
HBV disease was more common in individuals with history of active and passive smoking. The International Agency for Research on Cancer (IARC) has classified HCC as one of the tobacco related cancers in 2004. Cigarette smoke contains hundreds of different carcinogens that promote HBV infection. Although, independent effects of $\mathrm{HBV}$ infection and cigarette smoking on the risk of $\mathrm{HCC}$ have been established; the possible interaction between these factors is not well characterized. Also, in Pakistan it is common to be passive smoker and smoking is practiced at public places and in public transports. There are rules for not smoking in public places and transports but the implementation of these rules are not commonly practiced $[14,15]$.

One other important finding of our study was high prevalence of HBV in individuals with dental care procedures. Hepatitis B was most common in individuals ever had dental care. Hepatitis B disease can be transmitted through dental care procedure due to unhygienic conditions and use of unsterilized equipment in dental care clinics. In Pakistan, especially in poor rural settings updated sterilization techniques are rarely used in dental clinics which mostly result in infectious diseases including Hepatitis B. There can be substantial decrease in the HBV infectivity only by following good clinical hygiene practices [16].

HBV prevalence was more common in individuals with low socioeconomic status. This trend is also more common in developing countries. We considered income defined according to Organization for Economic Co-operation and Development (OECD). Usually higher socioeconomic status individuals would have more opportunities and resources to access health care and can maintain healthier nutrition. The results also concluded that individuals with balanced nutritional status had less chances of having Hepatitis B disease [17, 18]. 
We also collected data about vaccination history and occupational history. Surprisingly, $46.3 \%$ individuals (results not shown) were not vaccinated for HBV and all individuals confirmed as serologically positive for HBV were not vaccinated. Although, Hepatitis B vaccinations are included in national immunization programmes, but individuals often miss vaccinations for different reasons including lack of awareness, resources, accessibility and quality of vaccinations. Sometimes, it is also common in societies where they do not vaccinate their children for some baseless religious reasons. Regarding occupational history, none of the individuals was working in Hepatitis B risk related environment.

\section{Conclusion and limitations}

In conclusion, individuals with no education and low socioeconomic status are more prone to Hepatitis B infection. Also, Smoking either active or passive is significantly positively correlated with Hepatitis B disease. The study also conclude that unhygienic practices particularly in dental clinics substantially increase the risk of Hepatitis B. The results of this study need to be interpreted with caution as the study had the limitations. This study was done with cross sectional study design therefore, the causal relationships between HBV positive individuals and various socioeconomic status factors could not be definitively established.

\section{Authors' contributions}

Conceived and designed the experiments: MW Khan \& H Ullah, Performed the experiments: H Ullah \& A Ullah, Analyzed the data: MW Khan \& H Ullah, Contributed materials/ analysis/ tools: H Ullah \& A Ullah, Wrote the paper: H Ullah.

\section{Acknowledgement}

Authors would like to thank the lab technician Assa Lab, Saleem medical complex, Balochistan, Pakistan for his technical support and assistance.

\section{References}

1. Sarin SK, Kumar M, Lau JK, Abbas Z, Chan LHY \& Chen CJ (2016). Asian pacific clinical practice guidelines on the management of hepatitis B: a 2015 update. Hepatol Inter 10(1): 1-98.

2. Wasley A, Moran DK, Kuhnert W, Simard EP, Finelli L \& Quillan GM (2010). The prevalence of Hepatitis B virus infection in the United States in the era of vaccination. J Infect Dis 202(2): 192-201.

3. Li L, Wu B, Yang LB, Yin GJ \& Liu JY (2013). Chronic Hepatitis B Virus Infection and Risk of Pancreatic Cancer: A Meta-analysis. Asian Pac J Cancer P 14(1): 275-279.

4. Machado DFGDP, Martins T, Treviso DJ, Silva RAV, Schiavon JLN, Treviso FS \& Schiavon LDL (2013). Prevalence and Factors Associated with Hepatitis B Virus Infection Among Senior Citizens in a Southern Brazilian City. Kowsar Corp 13(5): e7874.

5. Li W, Jiang Y, Wang Z, Jin J, Qi Y, Chi $X$, Zhang $H$, Feng $X$ \& Niu J (2015). Natural Killer p46 Controls Hepatitis B Virus Replication and Modulates Liver Inflammation. PLOS ONE 10(8): e0135874.

6. Anjum F, Ghayas S, Shafi V, Bashir L \& Naz S (2013). Trends in the Diagnosis and Treatment of Chronic Hepatitis B in Karachi Pakistan. J Med 14(1): 57-61.

7. Ayatollahi J, Ayatollahi A, Ayatollahi R, Ardekani AM \& Shahcheraghi SH (2014). Compliance With Hepatitis B Vaccination Among Adult Males With Sexually Transmitted Infections. Jundishapur J Microb 7(8): e11090.

8. Amano K, Kawaguchi T, Kuromatsu R, Kawaguchi A, Miyajima I, Ide T, Kakuma T \& Sata M (2014). Time trends of clinical characteristics in hepatocellular carcinoma patients with chronic hepatitis B virus infection A field survey between 2000 and 2012. Mol Clin Oncol 2(6): 927-934. 
9. Karaksy HEM, Mohsen LM, Saleh DA, Hamdy MS, Yassin NA, Farouk M, Salit ME \& Shabrawi MH (2014). Applicability and efficacy of a model for prevention of perinatal transmission of hepatitis B virus infection: Single center study in Egypt. World J Gastroentero 20(45): 1707517083.

10. Khan MW, Arbab M, Murad M, Khan B \& Abdullah S (2014). Study of factors affecting and causing low birth weight. J Sci Res 6(2): 387-394.

11. Razaq S, Khan MW, Masood Z, Malik A, Rehaman H, Rehmat N \& Jamil N (2015). An investigation on the prevalance of gestational diabetes mellitus in the pregnant women of province balochistan. World J Med Sci 12(2): 198-203.

12. Tseng YR, Wu JF, Kong MS, Hu FH, Yang YJ, Yeung CY, Huang FC, Huang IF, Ni YH, Hsu HY, Chang MH \& Chen H (2014). Infantile Hepatitis B in Immunized Children Risk for Fulminant Hepatitis and Long-Term Outcomes. PLOSE ONE 9(11): 111825.

13. Kim SJ, Han KT, Lee SY \& Park EC (2015). Quality of life correlation with socioeconomic status in Korean hepatitis-B patients: a cross sectional study. Health Qual Life Out 13: 55-66.

14. IARC (2004). Evaluation of Carcinogenic Risks to Humans: Tobacco Smoke and Involuntary Smoking. IARC Monog Eval Carc 83: $1-1452$.

15. Chuang SH, Lee YCA, Hashibe M, Dai M, Zheng T \& Boffetta P (2010). Interaction between Cigarette Smoking and HBV or HCV Infection on the Risk of Liver Cancer: A Meta Analysis. Cancer Epidem Biomar 19(5): 12611268.

16. Mahboobi N, Porter SR, Karayiannis P \& Alavian SM (2013). Dental Treatment as a Risk Factor for Hepatitis B and C Viral Infection, A Review of the Recent Literature. $J$ Gastrointestin Liver Dis 22(1): 79-86.

17. Stuver SO, Pinto CB \& Trichopoulos D (1997). Infection with hepatitis B and $\mathrm{C}$ viruses social class and cancer. IARC Sci Publ 138: 319-324.

18. Murad M, Arbab M, Khan MB, Abdullah S, Ali M, Tareen S \& Khan MW (2017). Study of factors affecting and causing preterm birth. JEZS 5(2): 406-409. 